
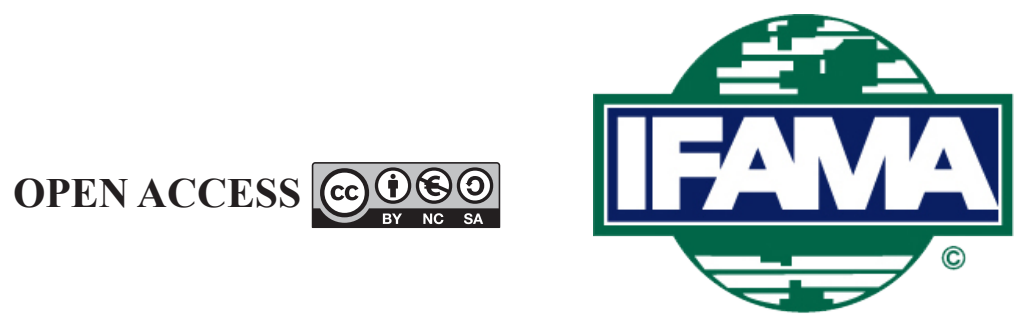

International Food and Agribusiness Management Review

Volume 24, Issue 3, 2021; DOI: 10.22434/IFAMR2020.0079

Received: 26 May 2020 / Accepted: 9 November 2020

\title{
The trade-off between chain performance and fragility considering coordination strategies of agri-food chains: a South African egg chain's case study
}

\author{
RESEARCH ARTICLE \\ Letlama Setene $^{\circledR a}$ and Daniel du P.S. Jordaan ${ }^{\mathrm{b}}$ \\ ${ }^{a}$ MSc Student, ${ }^{b}$ Lecturer, Department of Agricultural Economics, Extension and Rural \\ Development, University of Pretoria, Lynnwood Road, Pretoria, 0002, South Africa
}

\begin{abstract}
The mainstream strategy in the coordination of agri-food chains has traditionally focused more on the enhancement of chain performance by adopting lean and highly integrated strategies. These strategies are premised on the principle that governance structures are the result of tactics that economize on transaction costs in exchanges in chains. Due to existing interdependencies between chain players such strategies expose these chains to detrimentally disruptive uncertainty. This paper adopted a heuristic stress-testing approach to measure the fragility of South African egg value chain and performed a comparative fragility analysis of two coordination approaches in the egg chain. Additionally, the analysis of results indicated that the egg chain strategy with high levels of interdependencies between its chain players as significantly fragile. Precisely, the difference between the chain strategies was associated with a variety of differences at the factor and chain player levels that led up to a higher overall chain fragility of the chain with higher levels of interdependency. Inevitably, the paper propositions that there is a trade-off between chain performance and fragility. The results of the study affirmed that there is a trade-off between chain performance and fragility which needs to be balanced.
\end{abstract}

Keywords: coordination strategies, chain performance, chain fragility, interdependencies, uncertainty, agri-food chains

JEL code: Q13, L14, D80, M00

${ }^{\oplus}$ Corresponding author: letlamasetene9@gmail.com 


\section{Introduction}

The South African egg value chain is intensively coordinated (Bailey, 2016; Ncube, 2018); with lean logistics operations (Maslaric et al., 2013); just-in-time production (Maslaric et al., 2013); and globalised chains (Bosman, 2006; Enyinda, 2009). The concept of chains pursuing an integrated chain management is influenced by cost efficiency strategies which involve objectives like reducing transaction costs, improving customers' satisfaction, gaining competitive advantage and adhering to hazard analysis and critical control points (HACCP) (Serdarasan, 2013). The chain players use cost-efficient strategies by using strategies of coordination that are intensively tight and vertically linked (Williamson, 1979, 1987, 2008).

The lean and vertically integrated strategies are believed to enhance chain performance and result in the competitive advantage of a chain (Anand and Grover, 2015; Bailey, 2016; Liu et al., 2012; Storey et al., 2006). The intrinsic belief in improved chain performance suggests that the development of partnerships or ownership of the value chain results in better product flow, information transparency, and money-flow throughout the chain (Martinez, 2002a,b; Mentzer et al., 2001; Peterson et al., 2001). Martinez (2002a) adds that vertical coordination strategies such as vertical integration and contracts enhance production efficiency in the US poultry sector. Louw et al. (2017) highlight that increased vertical coordination in the South African commercial broiler industry enables the industry to accommodate and manage advanced technological changes.

Although increased vertical coordination contributes considerably to the performance and competitiveness of value chains, it also results in interdependencies and interconnectedness between chain players (Wever $e t$ al., 2012a). The existence of interdependencies between chain players (Jordaan, 2017; Lazzarini et al., 2001; Wever et al., 2012a) can be either by types or channels (Thompson, 2003). For instance, chain players can be interdependent in the same channels through their involvement in similar systems of quality management (Van Plaggenhoef, 2007; Wever et al., 2010) and by producing under the same brand (Raynaud et al., 2005).

The nature and extent of the interdependency between chain players is an aspect of the reciprocal action between risks and their impacts across the entire chain (Wever et al., 2010). High levels of interdependency between chain players expose the value chain vulnerability to new forms of risks resulting from increased vertical coordination (Elms and Low, 2013). These new forms of risks are inappropriately named 'systemic risks' and can cause the collapse of a value chain if any link is disrupted (Martínez-Jaramillo et al., 2010). These systematic risks are referred to as 'detrimental events that cause disruptive chaos to the normal functioning of a chain' (Jordaan, 2017).

Agri-food chains increasingly face disruptive events that have the low probabilities of occurrence with the significant impacts. That is, businesses and their chains face uncertainties that are hard to predict and even to manage (Jordaan, 2017; Vilko et al., 2014). These uncertain events result in irreparable, disastrous outcomes that threaten the continuity of a business (Engber, 2012; Kleindorfer and Saad, 2005; Leat and Revoredo-Giha, 2013; Zsidisin et al., 2005). Therefore, the consideration of value chain vulnerability relates to its exposure to detrimental disruptions (Christopher et al., 2002), and escalating vulnerability as harmful stressor relates to chain fragility (Jordaan, 2017).

For clarity, Jordaan (2017) defines chain fragility by putting it in context. He emphasises that 'a fragile chain implies that a 'break', or 'adverse event', in one link in the chain results in an accelerating impact, or nonlinear feedback, into the rest of the chain'. This means that the unforeseen detrimental event's impact on either one or more chain players can have similar effects on the next chain players because of interdependencies between these chain members brought on by increased vertical coordination (Jordaan and Kirsten, 2019).

This paper propositions that there is a trade-off between the performance of the agri-food chain and its fragility. Other researchers focused only on-chain performance while neglecting fragility. Given the trade-off between performance and fragility, it is important to consider both when considering coordination strategies 
to chain players in any particular industry. The lack of research considering both performance and fragility in the egg industry suggest that there is no scientific evidence to recommend a coordination strategy that balances performance and fragility in the South African egg industry. Therefore, the purpose of this study is to address this missing gap in the existing knowledge.

\section{Increased vertical coordination and chain performance}

The lean and highly integrated strategies of increased vertical coordination act as the way for agri-food chains to reduce the costs of transacting and to attain production efficiency (improved chain performance) (Martinez, 2002b). The reduction of transaction costs via vertical coordination can be influenced by transaction attributes (Hobbs, 1996), while the achievement of improved chain performance via increased coordination can be because of market uncertainties such as price and quality instability (Martinez, 2002b), technological advances (Louw et al., 2017; Martinez, 2002b), and production expectations (Ncube, 2018).

Many studies support the idea that increased vertical coordination in association with cost-reducing strategies encourages chain performance. For instance, Fischer et al. (2009) highlighted that repeated economic exchanges build trust and ultimately improve firms' performances and of that of their supply chains. They also observed that a high frequency of transactions in the ethanol supply chain led to increased coordination. Weseen et al. (2014), the empirical study indicates that increased vertical coordination is a preferred governance mechanism to reduce transaction costs against investment in specific assets. Then, Watabaji et al. (2016) highlight that uncertainty in exchange situations between a farmer and a trader, and also between a malt factory and a trader, has a positive correlation with value chain integration. Thus, farmers and traders go for integration to avoid or minimize any possible risks in their transactions.

Consequently, transaction mechanisms such as contracting, alliance formations and vertical integration seem to be the most preferred governance mechanisms that massively reduce transaction costs in firms' value chains and in return contributes positively to firms' supply chain performance (Cadot, 2015; Martinez, 1999, 2002b; Pieri and Zaninotto, 2013; Weseen et al., 2014; Zhong et al., 2018). Although these mechanisms are costefficient strategies and improve chain performance, they become sources of exposure for risks, uncertainty and chain disruptions (Bailey, 2016; Gray and Boehlje, 2005; Jordaan, 2017; Jordaan and Kirsten, 2019).

\section{Risk, uncertainty, and disruptions in value chains}

Modern value chains seem to face increasing uncertainty, exasperated by how these chains are coordinated and strategized - for instance, reduced lead-time, globalisation of the successive operations, outsourcing, and increasing vertically linked chains (Sheffi and Rice Jr, 2005; Sodhi et al., 2012; Zsidisin et al., 2005). Gray and Boehlje (2005) state that 'the development of more tightly aligned supply chains creates new and less easily quantifiable risks for the participants in the supply chain'. Kleindorfer and Saad (2005) mention that firms, together with their entire value chains, face rising vulnerability because their value chain designs are intensive, lean, and efficient.

These increasing uncertainties are known to be major value chain disruptors (Bailey, 2016; Christopher et al., 2002; Jordaan, 2017; Jüttner et al., 2003; Kleindorfer and Saad, 2005; Simba et al., 2017; Vanany et al., 2009). The risks and uncertainties that are used in value chains based on risks probabilities and impacts, do not present a true picture because the probabilities are merely subjective (Vilko et al., 2014). The assessment of uncertainty in chains by Vilko et al. (2014), considers that 'all influential environmental factors are therefore impossible, and information based on which probabilities are formed is more or less imperfect'.

So, Vilko et al. (2014) emphasise that uncertainty in the context of value chains should be 'examined through the lenses of substantive and procedural uncertainty'. They give more clarity by defining both uncertainty concepts: 
Substantive uncertainty derives from the incompleteness of information set and it relates to a lack of information about environmental events and all information which would be necessary to make decisions with certain outcomes ... [while] procedural uncertainty arises from the inability of agents to recognise and interpret the relevant information even when available. It concerns the competency gap in the problem solving and limitations on the computational and cognitive capabilities of agents to pursue unambiguously their objectives, given available information (Vilko et al., 2014).

These risks and uncertainties have given rise to a growing impetus for value chains to consider the risks and uncertainties that affect value chain management (Kleindorfer and Saad, 2005), and to consider the identification and mitigation of these uncertainties with low probabilities that have catastrophic impacts (Norrman and Jansson, 2004; Zsidisin et al., 2005).

The paper's proposition that there is a trade-off between the performance of the agri-food chain and its fragility, is brought by the conceptual framework of increasing vertical coordination in response to transaction costs and risks associated with agri-food chains.

\section{Conceptual framework}

Agri-food chains differ from other industries' chains - such as automotive, manufacturing, and digital because of their characteristically biological nature (Clay and Feeney, 2019; Sporleder and Boland, 2011). Agri-food chains possess products that are perishable by nature (Behzadi et al., 2018; De Keizer et al., 2017; Weseen et al., 2014), are highly varied in their quality (Akerlof, 1970; Martinez and Zering, 2004; Migliore et al., 2015), and are exposed to uncertainty (Assefa et al., 2015; Behzadi et al., 2017). A widely known and distinct feature of agribusiness systems is the biological nature of their chains (Jordaan, 2017), which influences the chain managers or practitioners to adopt vertically tight coordination strategies (Gereffi, 2014; Handayati et al., 2015; Ye et al., 2018).

The vertically linked coordination of value chains is influenced by technological advances, compliance, regulatory changes, and socio-economic elements (Contò et al., 2013; King et al., 2010; Sexton, 2012). Furthermore, agri-food chains face other challenges such as 'input/output price risks, quality/quantity risks' (Jordaan, 2017), and food safety concerns which influence increased vertical coordination (Jordaan, 2017). These challenges influence transformation of chains' operations from informal market structures such as the open market to formal market structures such as contracting, alliance formation, and vertical integration to reduce costs of transacting (Hobbs, 1996; Kirsten et al., 2009; Peterson et al., 2001; Weseen et al., 2014; Williamson, 2008).

Increased vertical coordination to reduce transaction costs is influenced mainly by three attributes: (1) investment in relationship-specific assets; (2) the frequency of economic exchange, and (3) uncertainty surrounding that exchange (Crook et al., 2013; Hobbs, 1996; Masten, 1996; Weseen et al., 2014; Williamson, 1979). The increased vertical coordination is based on pursuing of cost-efficient strategies, and on improving the performance of value chains (Bijman et al., 2011; Martinez, 2002b; Wang et al., 2006; Zhong et al., 2018).

However, improving chain performance seems to be possible only under conditions that do not involve uncertainty (Jordaan, 2017; Sexton, 2012). The notion is that vertically linked chains conceal systemic risks that are potentially detrimental and disruptive as a result of the interdependencies and interconnectedness (Wever et al., 2012a) between those chains' stakeholders (Christopher et al., 2002; Jordaan, 2017; Wagner and Bode, 2006; Wagner and Neshat, 2010).

The interdependencies and interconnectedness (Jordaan, 2017; Lazzarini et al., 2001; Wever et al., 2012a) come with 'systematic risks and complex payoffs' (Jordaan, 2017) that are vulnerable under an uncertain environment within and around the value chains (Sexton, 2012). As a consequence, the risks expose the fragility of value chains (Jordaan, 2017; Peck, 2005), since fragile chains 'introduce new strategic risks 
which will require additional analysis and/or skills to manage or mitigate those risks' (Gray and Boehlje, 2005) far beyond what is normally known.

Modern agri-food chains face unpredictable and risky events that are hard to manage (Jordaan, 2017). It is thus imperative to improve the risks management strategies of the value chains because they are a crucial part of continuous firms' operations (Leat and Revoredo-Giha, 2013). The conceptual framework (Figure 1) of this paper considers the fragility of the South African egg value chain. In essence, it is strategically important for the agri-food chains' players 'to deal with the trade-off between high performance and fragile value properties of value chains' (Jordaan, 2017).

The proposition for a trade-off focuses centrally on the coordination of the agri-food chains, and, in particular, 'where the pursuit of chain performance is juxtaposed against the inevitable ruin of any vulnerable system'

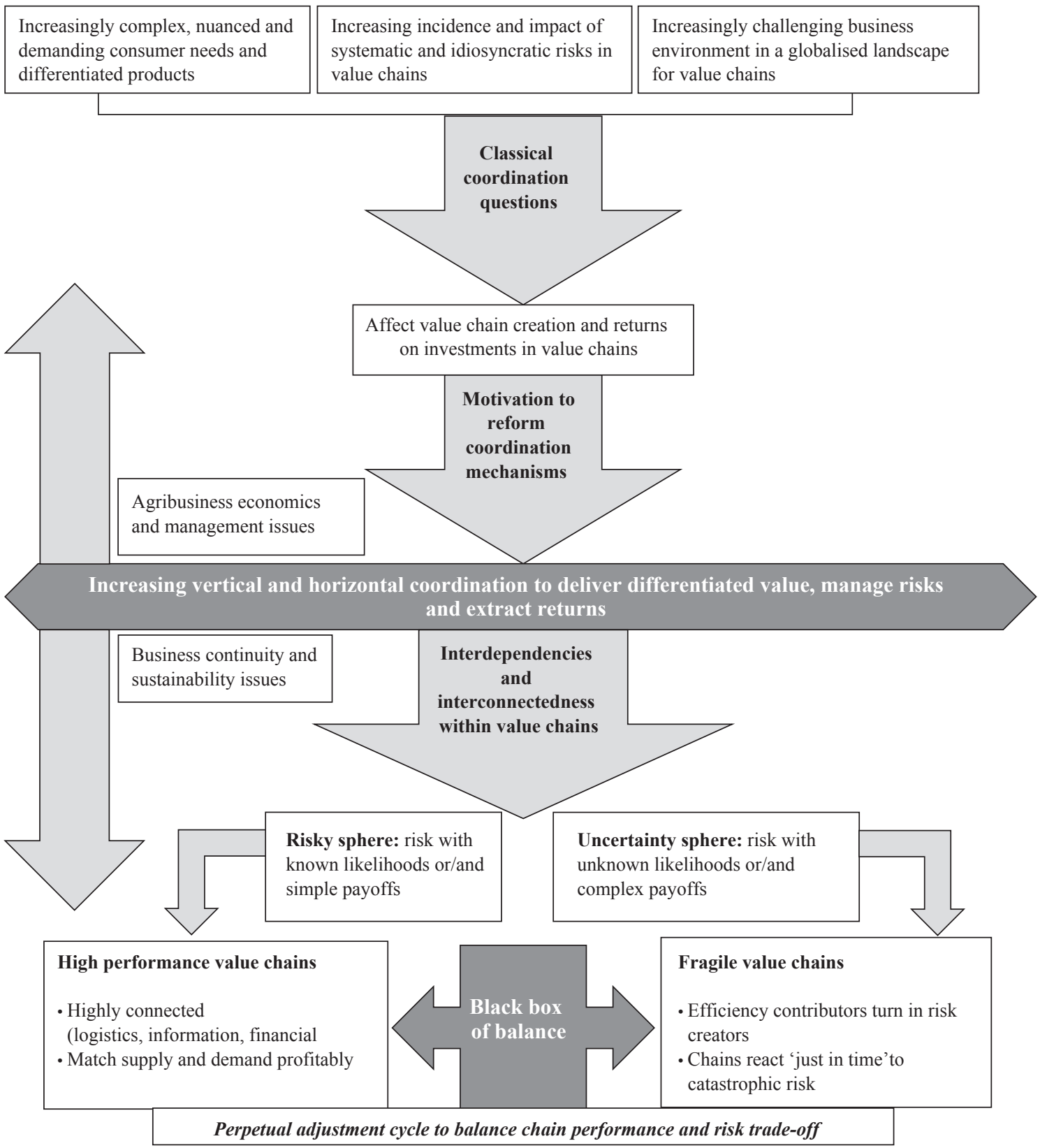

Figure 1. The conceptual framework of increasing vertical coordination and fragility (Jordaan, 2017). 
(Jordaan, 2017). The argument of Taleb (2012) supports this point by stating that anything fragile will break as time goes on. The conceptual framework provides a way to explore fragility as a phenomenon in the South African egg value chain and provides guidelines to address the proposition of the trade-off considering the chain coordination.

Profit maximisation or market share accumulation reflects the main goal of any economic exchange. Thus, risk management and business survival are subordinate goals for economic operations that maximise profits (Jordaan, 2017). Taleb (2012) makes a strong argument that 'what is missed is the strong logical precedence of the survival over success'. Jordaan (2017) adds that fragility mitigation is a crucial and compulsory activity of doing business. Although the arguments sound obvious, they are insufficiently emphasised.

As highlighted earlier that the interdependency and interconnectedness between chain players caused by pursuing cost effecting strategies play a vital role in exposing the chains to uncertainty. Then, the following section provides more clarity on these concepts in details.

\section{Interdependencies in value chains}

The nature of agri-food chains involves the specific exchange relationships that make most firms or chain players not internally self-sufficient concerning strategic and critical resources, resulting in interdependencies between activities (Kembro, 2015; Kembro et al., 2014; Peterson et al., 2001). Therefore, firms purposefully seek to manage these interdependencies by adopting cost-efficient strategies - which mainly are vertical and lean, such as contracts, alliance formations and vertical integration (Paulraj and Chen, 2007; Petersen et al., 2008; Ulrich and Barney, 1984). Although the strategies assist firms to manage these interdependencies between activities, they create interdependencies between chain players (Petersen et al., 2008; Skipper et al., 2008).

The value chain is composed of dyads that represent different relationships between chain players (Capaldo and Giannoccaro, 2015). Dyadic relationships involve complex interdependencies that influence the behaviour and performance of chain players (Nair et al., 2009). Also, the interdependencies become evident when the behaviour of the chain players in a dyad, and the outcomes of their behaviour, depending on the behaviour of other chain players in the chain (Jordaan, 2017; Wever et al., 2012a,b). Thus, there are some differences between the interdependencies that can be decided between the 'type' and the 'channel', in that all dyadic relationships among chain players are formed (Wever et al., 2012b).

The differentiation of interdependencies between chain players by 'type', as shown by the work of Thompson (2003), can be pooled (that is, independent), sequential, or reciprocal, depending on the dyadic relationships between those chain players (Dubois et al., 2004; Kembro, 2015; Lazzarini et al., 2001; Paulraj and Chen, 2007; Segerstedt et al., 2010; Skipper et al., 2008; Wever et al., 2012a,b). The independent (pooled) interdependency is regarded as a weak form of interdependence (Skipper et al., 2008) because chain players work together as more-or-less completely independent individuals who are loosely linked because they share common resources (Kembro, 2015; Wever et al., 2012a) - for example, egg layers using the same feeds from a single provider; thus all would be affected by the demand for the feeds.

Sequential interdependency involves direct linkages between chain players, whereby the inputs of one chain player are directly dependent on the output of another chain player (Kembro, 2015; Skipper et al., 2008; Wever et al., 2012a). In other words, sequential interdependence can be seen where activities of one chain player precede those of another (Lazzarini et al., 2001). For example, the broiler producer delivers broilers to an abattoir that then delivers them to a processor. These chain players have direct sequential linkages.

Last but not least, reciprocal interdependency occurs when the inputs of one chain player are directly dependent on the outputs of another chain player and vice versa (Lazzarini et al., 2001); (Skipper et al., 
2008; Wever et al., 2012a). Furthermore, there is a mutual exchange of inputs and outputs between chain players (Kembro, 2015).

The differentiation of interdependencies between chain players by 'channel' is a situation in which chain players may be interdependent via several interfaces (Borgatti and Li, 2009). The chain players can be directly or indirectly linked because of their engagement in systems such as quality management schemes (Martinez and Zering, 2004; Wever et al., 2010), or there may be some linkages between them because they produce for the same brand (Raynaud et al., 2005). Therefore, there is a connection between types and the channel of interdependencies. This means that there can be more than one interdependency type between chain players when their dyadic relationships are linked via multiple channels (Wever et al., 2012a). Also, Wever et al. (2012a) state that the channel in which chain players are interdependent influences the interdependency types between chain players, and vice versa.

The intensity of interdependencies between chain players affects systemic risks, as these interdependencies can contribute to the vulnerability of a chain that involves a series of interdependent economic exchanges (Mentzer et al., 2001). Wever et al. (2012a) support this by indicating that the type and the channel via which chain players are directly or indirectly linked model how these players would be influenced by externalities. Thus, the interdependencies expose agri-food chains to uncertainties and risks that may arise either internally or externally and cause disruptions (Jordaan, 2017).

\section{Vulnerability and fragility of value chains}

The design of the value chain, as previously stated, focuses more on maximising efficiency (improving chain performance) and speed by adopting cost-efficient strategies in fast-changing and competitive markets. However, 'this focus on efficiency has resulted in value chains that are more vulnerable to disruptions' (Stecke and Kumar, 2009). Thus, these disruptions increase the vulnerability of the value chain. It is reasonable to conclude, therefore, that the vulnerability of a value chain is an 'exposure to a harmful or serious disturbance or stressor, arising from risks within and external to the chain' (Christopher et al., 2002). Furthermore, the increased susceptibility of a chain extends into chain fragility (Jordaan, 2017). In other words, 'fragility extends the concept of vulnerability and is defined as an accelerating vulnerability to a harmful stressor' (Taleb et al., 2012).

The conceptualisation of fragility in agri-food chains is vital because, just like businesses, a chain can be either fragile or anti-fragile (Jordaan, 2017). Jordaan and Kirsten (2019) have assessed the fragility of the South African lamb value chain to address the concept of fragility in the value chain context. So, Jordaan (2017) comments that 'a fragile chain implies that a 'break' or 'adverse event' in one link in the chain results in an accelerating impact or non-linear feedback (negative impact) into the rest of the chain'. The 'non-linear feedback' or escalating sensitivity of an impact from an event implies the vulnerability of a system (Jordaan, 2017). As noted earlier by Taleb et al., (2012), 'fragility extends the concept of vulnerability and is defined as an accelerating vulnerability to a harmful stressor'.

The sensitivity of a system not only results in negative impacts (losses), but it also results in a positive impact (gains). This positive impact is known as anti-fragility (Jordaan and Kirsten, 2019; Taleb, 2012; Taleb et al., 2012). Taleb (2012) highlights that anti-fragility refers to a potential gain from exposure of something related to the beneficial occurrence. In other words, anti-fragility implies that whenever an unforeseen event occurs or agri-food chain faces uncertainty, that results in gains for it. This explanation brings in the concept of resilience and robustness in chains.

Both resilience and robustness are regarded as 'default defence against the revenge of uncertainty' (Jordaan, 2017). In the context of value chains, they are defined as the capability of chains to cope with unforeseen events or uncertainty with the main objective of recovering to maintain their continuity (Bevilacqua et al., 2017; Bruneau et al., 2004; Christopher and Peck, 2004; Pettit et al., 2019). In essence, this implies the chains' 
ability to return to their original states after being disrupted. Moreover, this brings in some differences between resilience, anti-fragility and fragility. The differences are that resilience means stability (ability to return to original state), anti-fragility means gains (obtain something useful, that give a firm or a chain a competitive advantage) while fragility means losses (harm or distress that comes from losing something) after facing unforeseen event. Thus, the analysis of fragility cannot be regarded simply as risk analysis (Jordaan, 2017).

There are differences in analysing fragility and in analysing risk for risk management. The analysis of risk entails frameworks that could assist with risk identification, assessment and mitigation for risk management practices (Altay and Green III, 2006; Kleindorfer and Saad, 2005; Nishat Faisal et al., 2006; Nooraie and Parast, 2016; Yeboah et al., 2014). Therefore, for value chain managers to execute risk management practices through risk analysis, they would need frameworks that already have 'reliable and accurate measures of risk' (Jordaan, 2017). This, in turn, can make it difficult or even impossible for chain managers to perform risk management because chains have recently faced risks and uncertainties that are said to be 'structural and procedural' (Vilko et al., 2014).

On the other hand, 'fragility analysis' can be regarded as the opposite of 'risk analysis' (Jordaan, 2017). Jordaan (2017) emphasises that analysing chain fragility using a risk management approach involves ascertaining a chain's vulnerability to detrimental events rather than dealing with these events' probabilities and impacts. This concurs with the argument of Taleb (2012) that 'it is far easier to figure out if something is fragile than predict the occurrence of an event that may harm it' - that is if an event involves 'structural and procedural' uncertainties (Vilko et al., 2014) that entail unpredictable probabilities and impacts. Some factors are either internal or external that drive the fragility of value chains (Jordaan, 2017).

\section{Factors that drive chain fragility}

A risk's relevance to chains dependents on the chains' attributes or features and the losses that firms incur due to the vulnerability of their chains arising from chain disturbances (Wagner and Bode, 2006). The complexity of the production process and of the chain itself (Hashemi et al., 2013), together with a chain's operational risks and disruption risks (Kleindorfer and Saad, 2005; Tang, 2006), are regarded as crucial components of uncertainty that affect the coordination of agri-food chains and their management (Jordaan, 2017). Thus, factors that are believed to influence fragility differ from sector to sector and from organisation to organisation (Stonebraker et al., 2009).

The literature highlights different possible fragility factors. They mainly constitute internal and external factors relating to value chains. Internal factors mainly include management, marketing, logistics, and sales operations (Jordaan, 2017; Jüttner, 2005; Stonebraker et al., 2009; Vlajic et al., 2012; Wagner and Bode, 2008). These factors are elements that involve adding value to the different processes of product development through to delivery to the consumer (Jordaan, 2017). The internal fragility factors include factors such as training of labour force, information and communication transparency, supplier and buyer reliability, performance of product quality and safety, firm cash flow position (Jordaan, 2017; Stonebraker et al., 2009).

On the other hand, the external factors mainly include compliance, legal and regulatory requirements, and social, economic, political, and environmental issues such as political unrest, natural disasters, state of the country's economy, quality of infrastructure, competitors' behaviour and lack of cooperation (Chopra and Sodhi, 2004; Coleman, 2006; Jordaan, 2017; Stonebraker et al., 2007, 2009; Vlajic et al., 2010, 2013). Such factors are known to arise from the environment within which the value chain is operating, and they have significant reverberations on some segments of the chain or on the entire value chain (Jordaan, 2017). Jordaan (2017) adds that this set of factors is based on the judgement that they influence the success of value chain operations.

Jordaan (2017) emphasises fragility factors that most studies don't consider: chain fragility factors. Their existence is the result of chains' complexities and how these chains are coordinated, together with the 
alignment between chain players (Jordaan, 2017). Also, as much as the chain coordination strategies and the tight alignment of chain players contribute massively to efficient chain performance, they become sources of exposure (Gray and Boehlje, 2005) to chain susceptibility, resulting in a rippling impact caused by chain disruption (Jordaan, 2017). These chain fragility factors are follows; supplier and buyer relationship and alignment, degree of chain complexity, information sharing with buyers, degree of chain-wide communication and the adequacy, accuracy, and relevance of data, its analysis, and effect on decision making (Jordaan, 2017).

\section{Methods}

\subsection{Measuring value chain fragility}

This study adopted the tool to measure value chain fragility by Jordaan and Kirsten (2019), which entailed presenting each of the listed value chain fragility factors explained above. The same procedure with the respondents is followed as that used by Jordaan and Kirsten (2019):

...the respondents' reactions were elicited in response to a progressively worsening adverse event, concerning the specific factor. The extent of adverse events was worsened in $10 \%$ increments from 10 to $90 \%$ and respondents were required to indicate the corresponding impact of the adverse event on their continuous businesses' operations in 10 equally sized incremental categories, ranging from $0-10 \%$ to $90-100 \%$.

As already stated, the measurement of fragility in the South African egg value chain was carried out using heuristic stress testing. This approach sought to evaluate the value chain's fragility rather than a specific incident that would reveal its fragility. This approach did not give a single measure that confines all fragility factors for South African egg value chain. Thus, a procedure is used to put in place a composite index for each value chain player, and then combine the composite indices of the respective chain players to come up with an outcome that indicates the chain's fragility (Jordaan and Kirsten, 2019).

\subsection{Comparative value chain fragility analysis}

The specific reason for choosing the heuristic stress testing approach was because Jordaan and Kirsten (2019) state that the approach gives the techniques to cross-examine the concept that there is some sort of relationship between the strength of a value chain's coordination strategy and its fragility. Therefore, as stated before, the approach does not give a single measure that confines all fragility factors for agri-food chain (Jordaan and Kirsten, 2019). To come up with a measure of fragility, Jordaan and Kirsten (2019) state that there is a development of 'a composite index per chain player and final score denoting 'value chain fragility', comprised of all the composite indices of each value chain player in the chain being analysed'.

As a result, to complete a single measure of fragility, a polygon is developed with final sub-index values, which entails the fragility of a particular chain that is being analysed (Gopal and Thakkar, 2015; Jordaan, 2017; Jordaan and Kirsten, 2019). For comprehensive details on this approach, Jordaan (2017) and Jordaan and Kirsten (2019) state their perspective as follows:

... the point where the axes meet corresponds to a value of 0 . The value corresponding to the edges of the polygon is 0.4461 . The larger the area of the polygon is, the greater the fragility of the individual stakeholder under analysis is. The area of the polygon is calculated by dividing the total area of the polygon into triangles. Then, using the formula $(0.5 \times a \times b \times \sin (360 / 17))$, the area of each separate triangle is calculated and summed to arrive at a total value for fragility.

Jordaan and Kirsten (2019) emphasise that the above-explained procedure is then used to combine the individual fragility scores per chain player into a composite index that represents the measure of fragility 
for the whole chain. For simplicity, Jordaan and Kirsten (2019) summarise the steps required to accomplish a measurement of a value chain's fragility:

- Step 1 - determine the fragility of each of the fragility factors for each player.

- Step 2 - combine each of the fragility outcomes per fragility factor into a composite index of fragility for each chain player.

- Step 3 - combine each of the fragility outcomes per chain player into a composite index of fragility for each chain.

To make a proposition that there is a trade-off between chain performance and chain fragility, the South African egg value chain is considered in two different configurations to compare its coordination strategies for a comparative analysis of its fragility.

- The first configuration of the chain incorporates the lower levels of the vertical linkages (low levels of interconnectedness and interdependency).

- The second configuration of the chain incorporates the higher levels of the vertical linkages (high levels of interconnectedness and interdependency).

Then the unequal variance $t$-test is used to test whether the average fragility of the two different egg market value chains, which possess different levels of interdependency among their chain players, are significantly different from each other. Below are two hypotheses for the activity.

- The null hypothesis: There is no statistically significant difference in the average chain fragility of the two different South African egg value chain coordination strategies.

- The alternative hypothesis: There is a statistically significant difference in the average chain fragility of the two different South African egg value chain coordination strategies.

The data collection was carried out through an emailed questionnaire and arranged interviews. A stratified and random sampling selection of the South African egg value chain players was conducted. The different activities in the chain were the strata, and within these strata, respondents were randomly selected sources. The data analysis was carried out using Microsoft Excel (Microsoft, Redmond, WA, USA).

\section{Overview of the respondents and accuracy of the sample size}

The total population size was 1,288 which was a make-up of 1,216 egg producers, 43 pullet rearers, and 29 retailers (DAFF, 2018; Igumbor et al., 2012; SAPA, 2017). The targeted sample size of 195 stakeholders in the South African commercial egg chain was invited to participate in the study; the questionnaire was then presented and distributed to them. However, the response rate was 37.4\% (73 stakeholders completed the questionnaires). The 73 respondents were a distribution of chain players within the egg industry, across the two egg chain configurations (higher levels of interdependency and lower levels of interdependency). Figure 2 shows the distribution of the sample size (73) across the South African egg value chain. The sample size

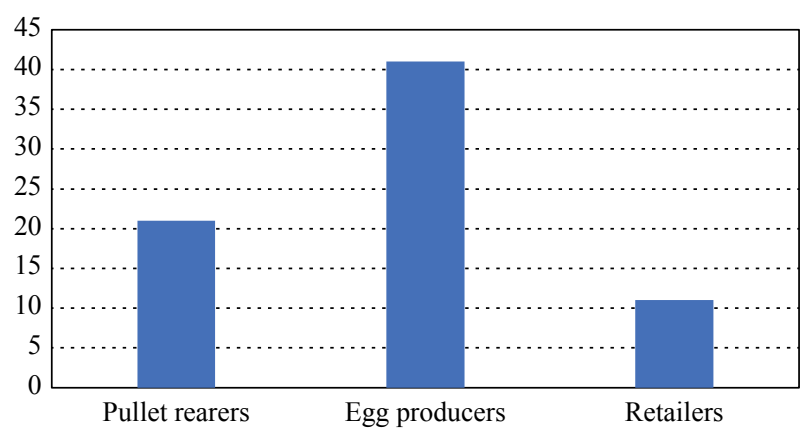

Figure 2. Distribution of respondents from South African egg chain. 
of 73 respondents offered a marginal error of $10 \%$ and a confidence level of $90 \%$ for the adequacy of the sample, given the total population size $(1,288)$.

\section{Results}

\subsection{Fragility scores per factor}

The results of the fragility analysis showcase a notable outcome of the average fragility scores of the fragility factors. The fragility scores result from two South African egg chain configurations representing two chains: one with higher levels of interdependency between its chain players (Figure 3), and the other with lower levels of interdependency between its chain players (Figure 4).

These scores confirm what Jordaan (2017) and Jordaan and Kirsten (2019) say about non-linear effects that are in correlation with the fragility of any particular factor. These effects ultimately indicate the susceptibility of a factor to unforeseen and highly detrimental events. Both Figure 3 and Figure 4 show the fragility scores per factor for each of the egg chain configurations and its chain players. The negative scores, which are known as the negative convexity effect, specify fragility, while the positive scores, known as the positive convexity effect, specify anti-fragility (Jordaan, 2017; Jordaan and Kirsten, 2019).

Based on the results presented in Figures 3 and 4, the fragility factors such as business operational reliability, products' quality and safety performance, supporting infrastructure, business's cash-flow position, and buyer and supplier reliabilities have high fragility scores.

Figures 3 and 4 also show the factors that display anti-fragility, because they possess positive convexity effects across both chains and for their chain players. These factors are the state of the economy and prices, social stability and public relations, information sharing with the buyer, and private and public compliance requirements. These positive convexity effects differ across the chain players in both configurations. The only two factors that display the effects for egg producers in both chains are social stability and public relations,

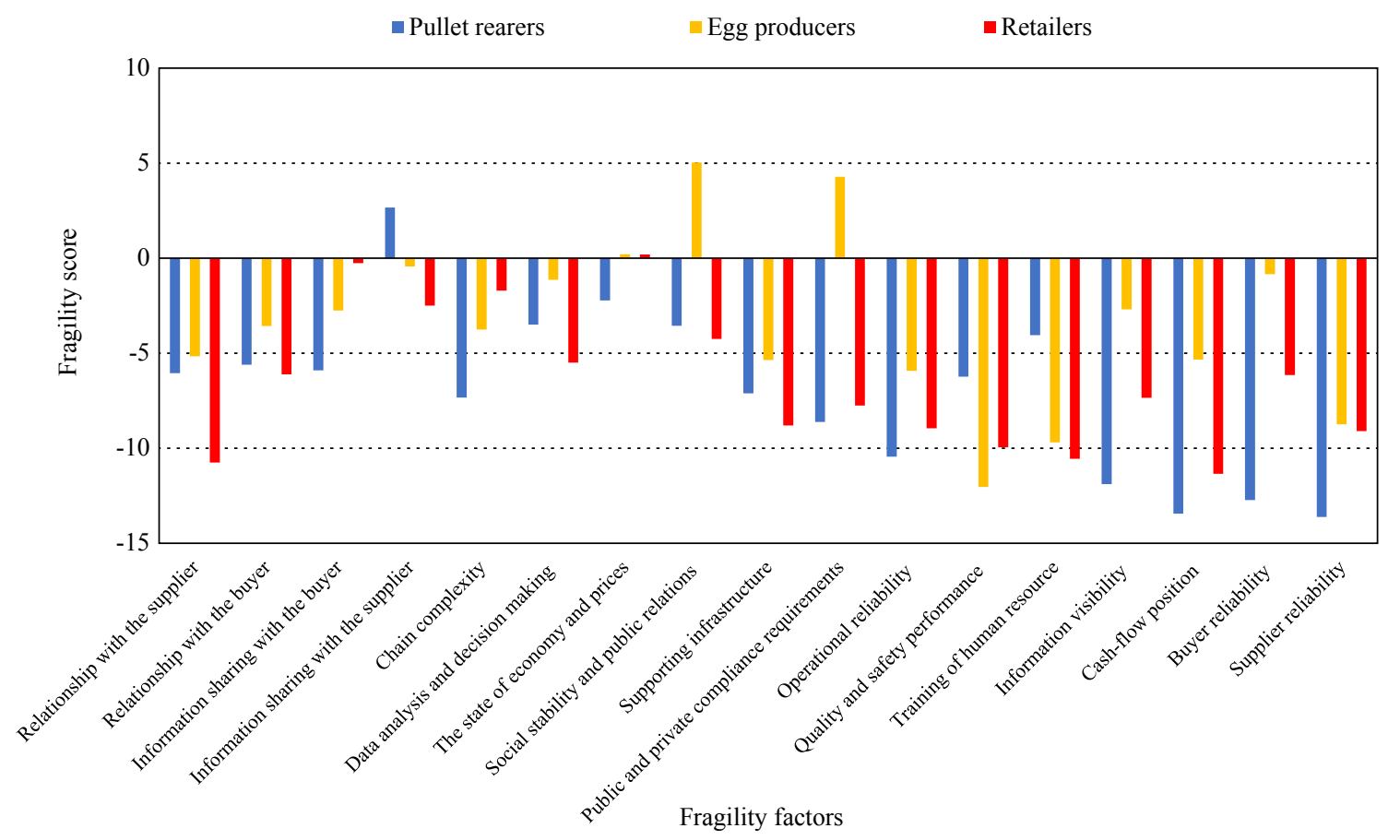

Figure 3. Average fragility per factor in South African egg chain with higher levels of interdependency. 


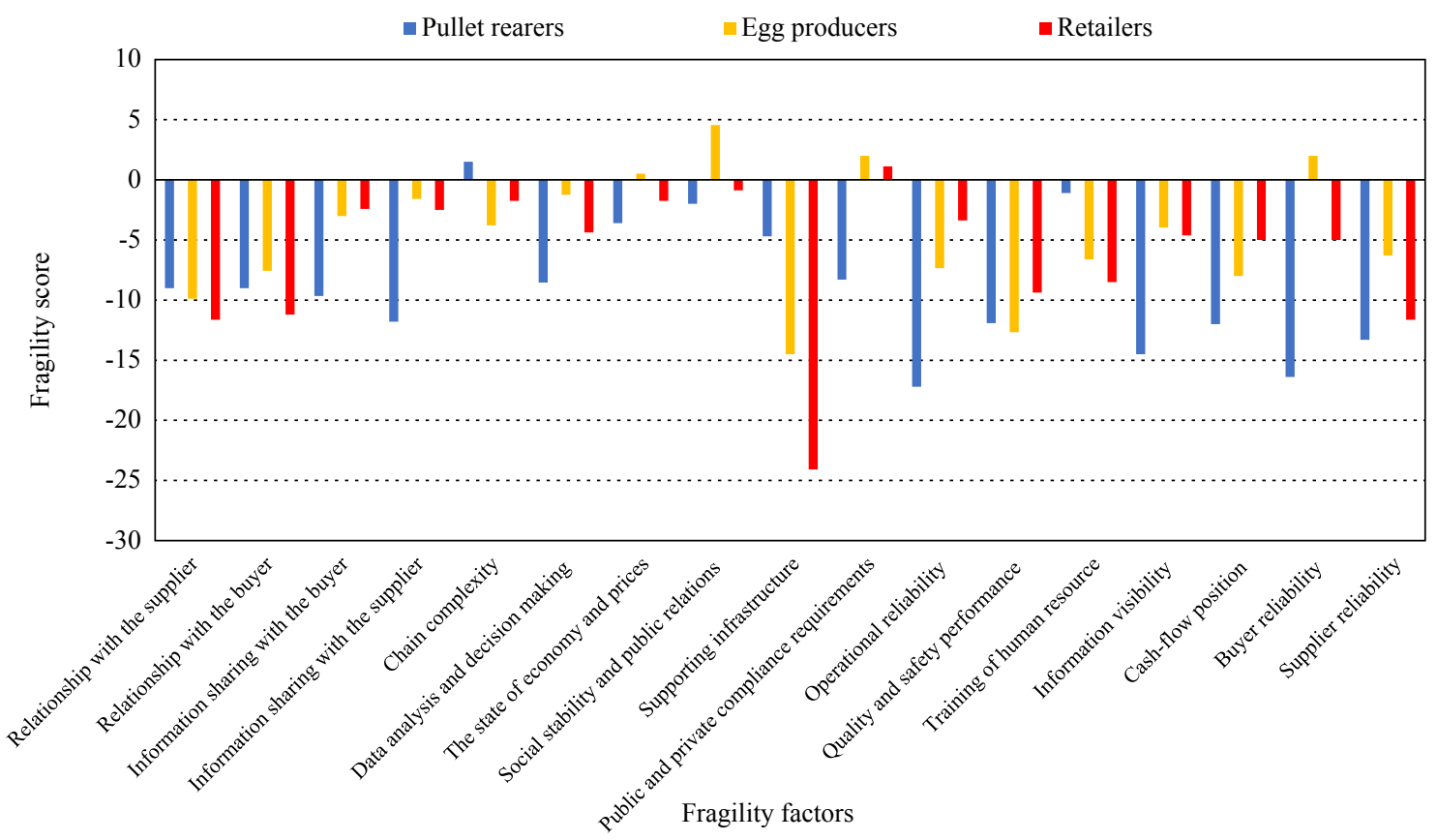

Figure 4. Average fragility per factor in South African egg chain with lower levels of interdependency.

together with private and public compliance requirements, while information sharing with the buyer is the only factor that displays the effects for pullet rearers that are in the chain configuration with lower levels of interdependencies. Last, the state of the economy and prices displays minimal effects for the retailers in both chains' configurations.

Although it is important to consider fragility scores per factor, it is also important to consider the fragility factor across the chain players in the same chain configuration. Also, the consideration ranks the most important factors per player to determine whether there is any convergence across the chain of the same factors. This determination provides important information and knowledge about which chain player is more exposed to uncertainty under that factor.

Therefore, in the chain configuration with higher levels of interdependencies, it is notable that the following factors are important to all chain players due to their higher fragility scores: supplier reliability, buyer reliability, cash flow position, and operational reliability. The following factors such as information visibility and relationship with the supplier are key for retailers. These factors imply that the retailers are facing a process of sharing critical information required to manage the flow of services, productions and information real-time between suppliers and customers.

On the other hand, the training of human resources and chain complexity are key factors for pullet rearers. The training of human resources implies having skilled staff to attain high-value eggs. While chain complexity implies a condition of interconnectedness and interdependency across a value chain, rather than a condition of being complicated. All chain players face drivers of complexity in a chain, which are issues related to a variety of suppliers, customers and interactions, demand amplification and conflicting policies (Serdarasan, 2013). However, the pullet rearers are most exposed to chain complexity in the South African egg chain.

The fragility factor that the egg producers most face is quality and safety performance requirements. This factor implies an assurance for safety and quality of eggs that are either imported or produced in South Africa are at set standards. The department of Agriculture, Forestry and Fisheries (DAFF) appointed an agency 
called Food Safety and Quality Assurance (FSQA), which deals with the regulation of agri-food products (eggs). Hence, the egg producers are the most exposed to this factor follower by retailers.

Furthermore, all these factors are vital for chain players in the chain configuration with lower levels of interdependencies. In other words, quite a few factors - such as operational reliability, quality and safety performance, and the training of human resources - are vital to pullet rearers and egg producers in the chain with lower interdependencies; supporting infrastructure is an important factor for retailers and egg producers, and the cash flow position is the only fragility factor that is key for all chain players in both egg chain configurations. Consequently, the chain players are exposed to uncertainty in different ways, even though they are in the same chain configuration. Figures 5, 6 and 7 show the fragility of each chain player in both chain configurations.

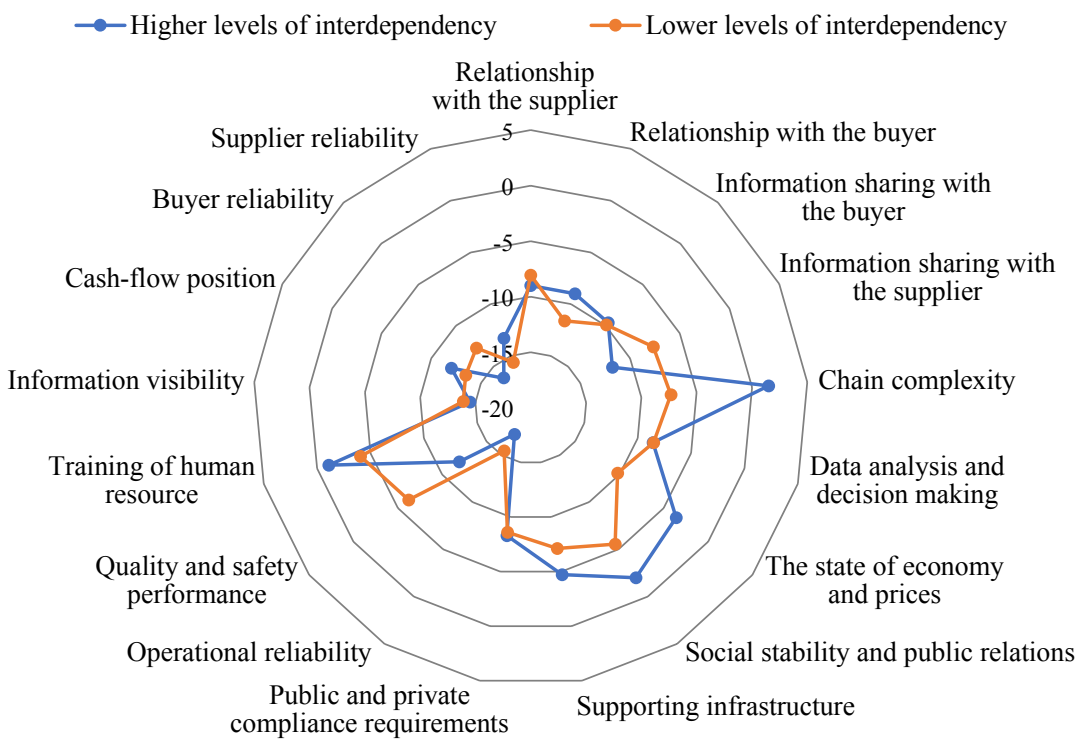

Figure 5. Fragility of pullet rearers in South African egg chain with lower levels of interdependency and with higher levels of interdependency.

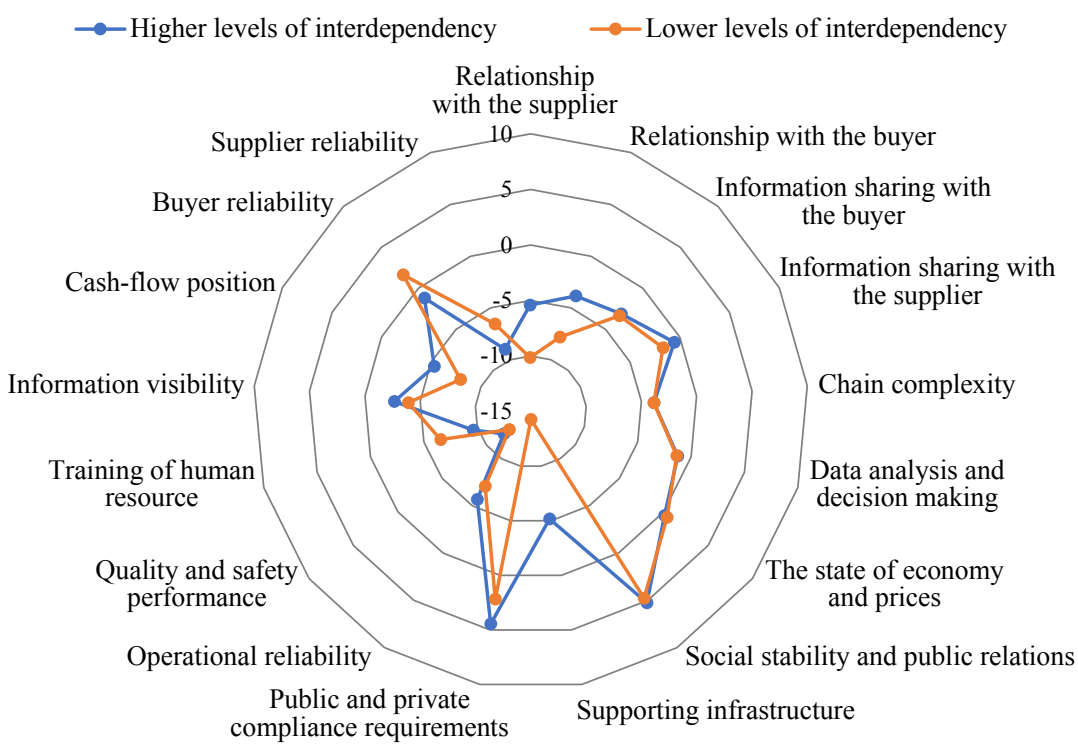

Figure 6. Fragility of egg producers in South African egg chain with lower levels of interdependency and with higher levels of interdependency. 


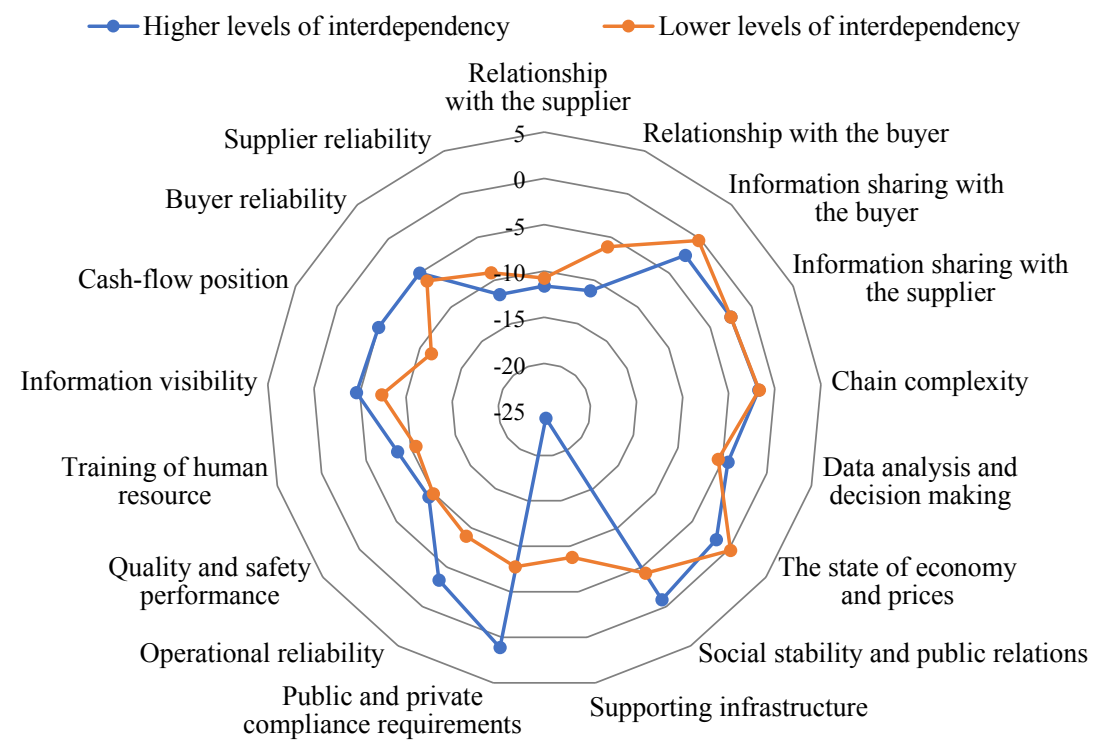

Figure 7. Fragility of retailers in South African egg chain with lower levels of interdependency and with higher levels of interdependency.

\subsection{Fragility per chain player}

The results of the fragility per chain player (Figures 5,6 and 7) show that pullet rearers and retailers have a higher exposure to fragility than do egg producers under both chain configurations. The results support the observations of Jordaan (2017) and Jordaan and Kirsten (2019) that there is a connection between the differences in the fragility factor per chain player and the equal size of the total fragility per chain player. As stated in methodology, 'the larger the area of the polygon is, the greater the fragility of the stakeholder under analysis is' (Jordaan and Kirsten, 2019). Thus, the observation supports the finding of Jordaan (2017) and Jordaan and Kirsten (2019) that the massive impact but infrequent incidence for a particular chain player could predictably have an indistinguishable impact on the other chain player.

A fascinating observation drawn from the results is that all the chain players in both chain configurations are differently exposed to fragility. That is, the chain players in one configuration with similar levels of interdependencies possess differences in the fragility they face. This means that the chain players are exposed to uncertainty differently. This suggests that, even though players have the same levels of interdependencies, their fragility scores differ due to their distinctive features. For instance, the pullet rearers are exposed to more uncertainty than are the egg producers and retailers in both configurations. That is, in whatever chain configuration they operate, that does not change anything, as they have sequential interdependencies in both chains. However, further reasons were not assessed, as that would have required further analyses that were beyond the scope of the study.

The differences in the fragility of any chain player under two chain configurations are what was expected, solely because the two chains have different levels of interdependency and interconnectedness between their chain players. Thus, the chain players of a chain that presents higher levels of interdependency between its members are exposed to more uncertainty than those in a chain that presents lower levels of interdependency between its members. Figure 8 shows comparisons of the fragility per chain player in the South African egg chain. The figure also supports the previous statement about the differences in fragility per chain player. 


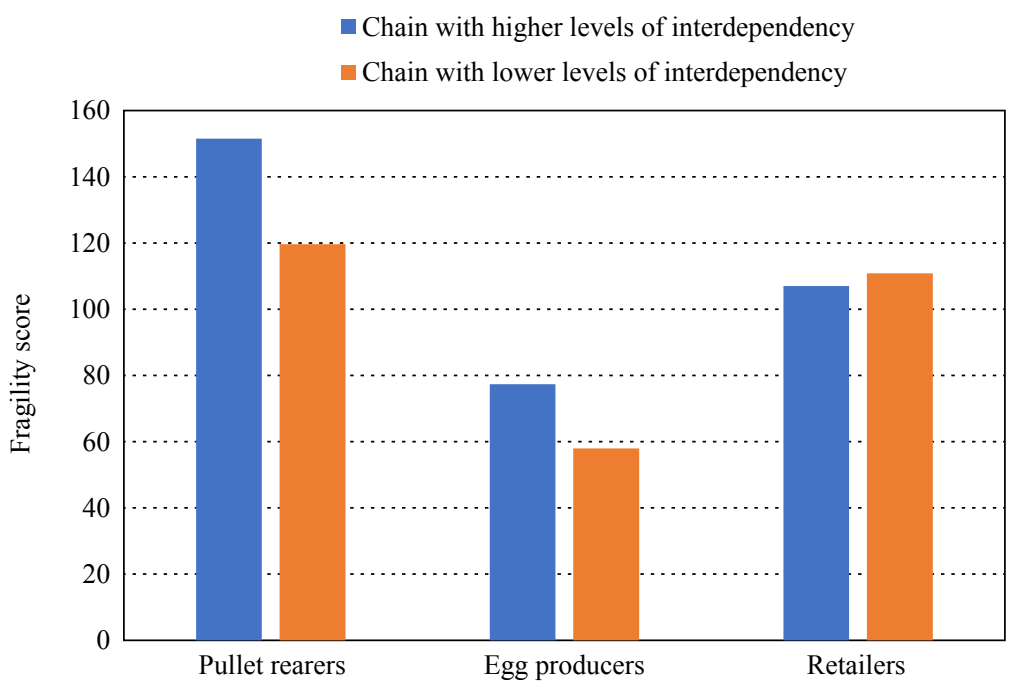

Figure 8. Comparison of fragility per chain player in two specified South African egg chains.

\subsection{Comparing the fragility of two egg chain configurations}

The purpose of the paper was to proposition that there is a trade-off between the performance of the agrifood chain and its fragility. To attain that the South African egg value chain's fragility had to be measured and the comparative fragility analysis between the two egg chain configurations had to be examined. All this was done by quantifying the fragility per factor and per chain player into chain fragility. Consequently, each of the two egg chain configurations has its nondescript value, which is proportional to the polygon's area (Figure 9). As illustrated earlier, the area of the polygon is calculated by dividing the total area of each polygon of the chain players (Figure 5, 6 and 7) into triangles. Then, using the formula $(0.5 \times a \times b \times \sin$ $(360 / 17))$, the area of each separate triangle is calculated and summed to arrive at a total value for fragility, and that represents a value chain's fragility (Jordaan and Kirsten, 2019).

Thus, the polygon's area in the egg chain with higher levels of interdependency between chain players is 225,815 , while the polygon's area in the egg chain with lower levels of interdependency between chain players is 114,624. Figure 9 shows the overall fragility of the South African egg value chain's two chain configurations.

The comparative analysis of the two chain configurations was performed. What has been found is that the egg chain with higher levels of interdependency was significantly more fragile than the one with lower levels of interdependency. Also, an unequal variance $t$-test was performed to justify the significance of the difference between the two chain configurations.

To justify the significant differences, the hypotheses of the study were tested as to whether the fragility averages of the two South African chain configurations were statistically and significantly different. Using a $5 \%$ level of significance and a degree of freedom of 30, the critical value of 2.042 under two tails was less than the calculated $t$-value of 2.364 . This indicated that the calculated $t$-value was greater than the critical value at a significance level of 5\%. Thus, the null hypothesis - that there is no statistically significant difference in the chain fragility means of the two South African egg value chain strategies - was rejected. The alternative hypothesis - that there is a statistically significant difference in the chain fragility means of the two South African egg value chain strategies - was therefore not rejected.

In this specific instance, the difference between the chains' configurations is associated with a variety of differences at the levels of the factor and the chain player (Figure 3, 4, 5, 6 and 7) that led to a higher overall 


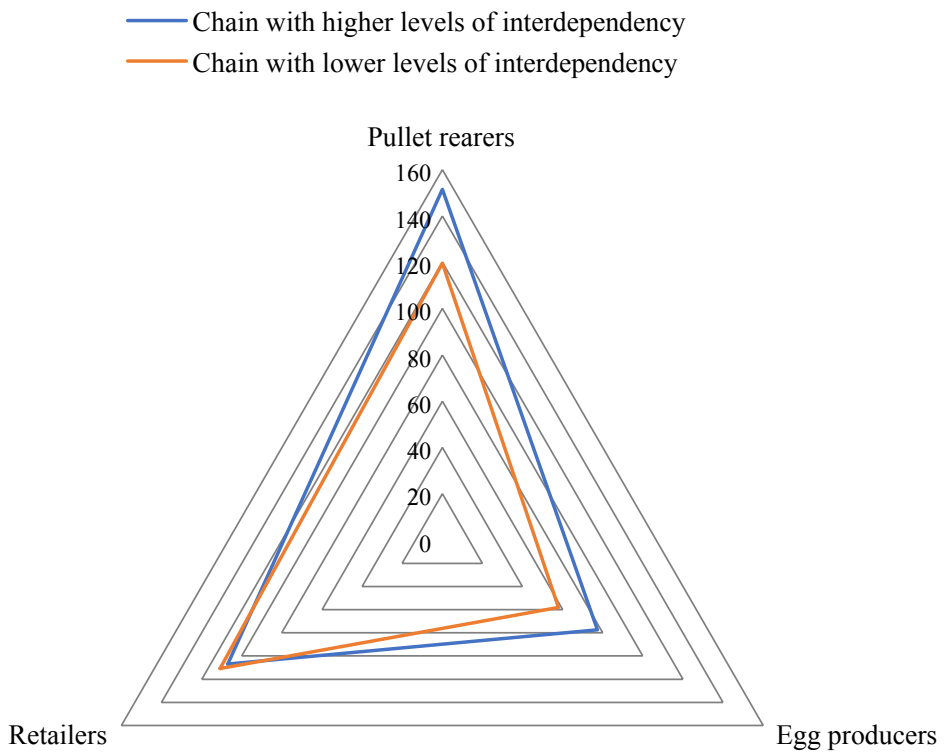

Figure 9. Comparison of overall chain fragility of two specified South African egg chains.

chain fragility (Figure 9) of the chain with higher levels of interdependency. That is the chain's higher fragility results from the extensive fragility at the levels of pullet rearers and retailers. Interestingly, this implies that the increased coordination intensity of South African egg value chains results in increased levels of interdependency between their chain players, which increases the fragility of the chain.

\section{Discussion}

The paper aimed to make a proposition that there is a trade-off between the performance of the agri-food chain and its fragility. This aim was attained by following the steps that are explained under methodology: (1) determining the fragility of each of the fragility factors per chain player (Figure 3 and 4); (2) combining each of the fragility outcomes per fragility factor into a composite index of fragility for each chain player (Figure 5,6 and 7); and (3) combining each fragility's outcomes per chain player into a composite index of fragility for each chain (Figure 9).

These steps of measuring the fragility of the chain are equally essential, as they enable a supply chain manager or an analyst to identify the causes or catalysts of the fragility at a specific level of analysis, which can be at factor level, chain player level, or chain level (Jordaan and Kirsten, 2019). Such comparative analysis can be done at any of those levels and is essential to trace and recognise the magnitude of such fragility. This measure of fragility for the South African egg value chain supports the finding of Jordaan and Kirsten (2019) that 'the ability to measure fragility, therefore, enables the prioritisation of factors for purposes of strategic decision-making at a range of levels in the chain'. Thus, at the factor level, a higher priority should be given to those fragility factors that have high fragility scores. These factors are a business's operational reliability, product quality and safety performance, the supporting infrastructure, a business's cash flow position, and supplier and buyer reliabilities (Jordaan, 2017; Jordaan and Kirsten, 2019; Stonebraker et al., 2009). However, the results have shown that these factors did not occur across all of the chain players.

Ultimately it is imperative to consider the fragility factor across chain players in the same chain configuration. Also, that consideration should rank the most important factors per player to determine whether there is any convergence of the same factors across the chain. In return, that determination should provide important information and knowledge that shows which chain player is more exposed to uncertainty for each factor. Thus, supplier reliability, buyer reliability, cash flow position, and operational reliability rank high in the chain configuration with higher levels of interdependencies (Wever et al., 2012b; Jordaan and Kirsten, 2019), 
while training of human resources and supporting infrastructure rank high in the chain configuration with lower levels of interdependencies (Jordaan, 2017; Stonebraker et al., 2009).

Some factors display anti-fragility because they possess positive convexity effects across both chains and for their chain players. These factors are the state of the economy and prices, social stability and public relations, information sharing with the buyer, and private and public compliance requirements (Jordaan, 2017; Jordaan and Kirsten, 2019). Their convexity effects differ from chain to chain. However, information sharing with the buyer is the factor that displays the positive effects in chain configuration with lower levels of interdependencies, while private and public compliance requirements rank high in the chain configuration with higher levels of interdependencies. However, the only two factors that rank high under both chains are social stability and public relations and the state of the economy and prices.

Figure 8 shows that, at chain player level, pullet rearers and retailers are exposed to higher uncertainty than egg producers because of their higher fragility scores. Therefore, the chain players are equally responsible for the task of fragility management for the entire South African egg value chain. Their responsibility mainly includes the discussion and restructuring of strategies that could assist with the reduction of fragility through the whole chain due to the existing interdependencies among themselves.

The comparative analysis of the two configurations of the South African egg value chain raised the relationship between strategies of coordinating and fragility. The results of the analysis show that transaction mechanisms such as vertical integration and contracting results in sequential interdependencies (Jordaan, 2017; Lazzarini et al., 2001; Wever et al., 2012a), which result in the increased fragility of a chain (Jordaan, 2017). These findings concur with those of Jordaan and Kirsten (2019) on the South African lamb value chain: that there is a relationship between increasing coordination intensity and increasing fragility. The findings also support an argument of Jordaan (2017) that 'increasing fragility is due to the increasing vertical coordination intensity and not that the coordination intensity is due to this fragility'.

Furthermore, the results also concur with the literature that suggests that leaner and highly integrated transaction mechanisms - such as contracting and vertical integration - are due to increased coordination as major ways to reduce costs and risks within supply chains (Cadot, 2015; Jordaan, 2017; Martinez, 2002a,b; Maslaric et al., 2013; Watabaji et al., 2016; Weseen et al., 2014). These coordinating strategies produce the interdependencies between chain players (Jordaan, 2017; Lazzarini et al., 2001; Wever et al., 2012a) and these interdependencies, in turn, expose the vulnerability of chains that pursue such lean and highly integrated strategies due to disruptive and detrimental events with very low likelihoods but huge impacts (Bailey, 2016; Christopher et al., 2002; Jüttner, 2005; Kleindorfer and Saad, 2005; Simba et al., 2017; Vlajic et al., 2013; Wagner and Bode, 2009; Wagner and Neshat, 2012). Also, increased chain vulnerability as a harmful stressor relates to chain fragility (Jordaan, 2017).

\section{Conclusions}

The main objective of the paper was to proposition that there is a trade-off between the performance of the agri-food chain and its fragility. The practical implication of the trade-off is that highly integrated and lean strategies improve chain performance by reducing transaction costs and risks in agri-food chains. However, these strategies increase the fragility of the chains (Jordaan, 2017; Maslaric et al., 2013; Wagner and Neshat, 2010, 2012). Thus, the important strategic choice for stakeholders in the South African egg industry and their value chains is to find a suitable coordination strategy that locates chain performance and fragility at the point of equilibrium (Nooraie and Parast, 2016). However, the concept of a trade-off between chain performance and fragility is only slightly discussed in the literature. For instance, Brede and De Vries (2009) highlight that efficient systems (chains with improved chain performances) are not robust (are fragile), while robust systems are inefficient. 
Also, the proposition is that both chain performance and fragile chain structures are essential requirements in the design of agri-food chains (Brede and De Vries, 2009; Jordaan, 2017). Thus, the trade-off is essential in the coordination of agri-food chains, signalling that there is an equilibrium between chain performance and fragility (Jordaan, 2017). The conceptual framework of the paper is a central point of this paper's proposition.

It is a priority for chain players of the South African egg value chain to consider fragility while perusing cost-efficient strategies. As Taleb (2012) says, "what is missed is the strong logical precedence of survival over success'. A fragile system or chain will surely break as time goes by (Taleb, 2012). Hence, the paper emphasised that there is a need of coordination strategies that would enable and improve their chain performance and contain chain fragility for South African egg firms, resulting in the attainment of chain performance and fragility at equilibrium. Further studies must be done to consider which coordination strategies could balance chain performance (efficiency/pursuit of opportunity/profit maximization/market accumulation) and fragility (vulnerability/risk and uncertainty).

\section{Acknowledgements}

Funding: This work was supported by the African Economic Research Consortium (AERC), through its Collaborative Masters in Agricultural and Applied Economics (CMAAE) programme.

\section{References}

Akerlof, G.A. 1970. The market for 'lemons': quality uncertainty and the market mechanism. The Quarterly Journal of Economics 84(3): 488-500.

Altay, N. and W.G. Green III. 2006. OR/MS research in disaster operations management. European Journal of Operational Research 175(1): 475-493.

Anand, N. and N. Grover. 2015. Measuring retail supply chain performance: theoretical model using key performance indicators (KPIs). Benchmarking: an International Journal 22(1): 135-166.

Assefa, T.T., M.P. Meuwissen and A.G. Oude Lansink. 2015. Price volatility transmission in food supply chains: a literature review. Agribusiness 31(1): 3-13.

Bailey, K. 2016. An investigation into risk and vulnerability in the UK food supply network. PhD-thesis, Cardiff University, Cardiff, UK.

Behzadi, G., M.J. O’Sullivan, T.L. Olsen and A. Zhang. 2018. Agribusiness supply chain risk management: a review of quantitative decision models. Omega 79: 21-42.

Behzadi, G., M.J. O’Sullivan, T.L. Olsen, F. Scrimgeour and A. Zhang. 2017. Robust and resilient strategies for managing supply disruptions in an agribusiness supply chain. International Journal of Production Economics 191: 207-220.

Bevilacqua, M., F. Ciarapica and G. Marcucci. 2017. Supply chain resilience triangle: the study and development of a framework. International Journal of Economics and Management Engineering 11(8): 2046-2053.

Bijman, J., R. Muradian and A. Cechin. 2011. Agricultural cooperatives and value chain coordination. In: A.H.J. Helmsing and S. Vellema (eds.) Value chains, social inclusion and economic development: contrasting theories and realities. Routledge, Oxford, UK, 82-101.

Borgatti, S.P. and X. Li. 2009. On social network analysis in a supply-chain context. Journal of Supply Chain Management 45(2): 5-22.

Bosman, R. 2006. The new supply chain challenge: risk management in a global economy. FM Global 4(6): $1-10$.

Brede, M. and B.J. De Vries. 2009. Networks that optimize a trade-off between efficiency and dynamical resilience. Physics Letters A 373(43): 3910-3914.

Bruneau M., S.E. Chang, R.T. Eguchi, G.C. Lee, T.D. O'rourke, A.M. Reinhorn, M. Shinozuka, K. Tierney, W.A. Wallace and D. Von Winterfeldt. 2004. A framework to quantitatively assess and enhance the seismic resilience of communities. Earthquake Spectra 19(4): 733-752. 
Cadot, J. 2015. Agency costs of vertical integration: the case of family firms, investor-owned firms and cooperatives in the French wine industry. Agricultural Economics 46(2): 187-194.

Capaldo, A. and I. Glannoccaro. 2015. How does trust affect performance in supply chain? The moderating role of interdependence. International Journal of Production Economics 166: 3-49.

Chopra, S. and M. Sodhi. 2004. Supply-chain breakdown. Massachusetts Institute of Technology Sloan Management Review 46(1): 53-61.

Christopher, M. and H. Peck. 2004. Building the resilient supply chain. The International Journal of Logistics Management 15(2): 1-14.

Christopher, M., A. McKinnon, J. Sharp, R. Wilding, H. Peck, P. Chapman and Y. Bolumole. 2002. Supply chain vulnerability. Cranfield University, Cranfield, UK.

Clay, P.M. and R. Feeney. 2019. Analyzing agribusiness value chains: a literature review. International Food and Agribusiness Management Review 22(1): 31-46.

Coleman, L. 2006. Frequency of man-made disasters in the $20^{\text {th }}$ century. Journal of Contingencies and Crisis Management 14(1): 3-11.

Contò, F., M. Fiore and P. La Sala. 2013. The role of innovation in the integration processes of integrated projects of the food chain: the case of the cherry cultivation chain in Apulia region. Intellectual Economics 7(4): 467-485.

Crook, T.R., J.G. Combs, D.J. Ketchen Jr and H. Aguinis. 2013. Organizing around transaction costs: what have we learned and where do we go from here? Academy of Management Perspectives 27(1): 63-79.

De Keizer, M., R. Akkerman, M. Grunow, J.M. Bloemhof, R. Haijema and J.G. Van der Vorst. 2017. Logistics network design for perishable products with heterogeneous quality decay. European Journal of Operational Research 262(2): 535-549.

Dubois, A., K. Hulthén and A.-C. Pedersen. 2004. Supply chains and interdependence: a theoretical analysis. Journal of Purchasing and Supply Management 10(1): 3-9.

Elms, D.K. and P. Low. 2013. Global value chains in a changing world: World Trade Organization, Geneva, Switzerland.

Engber, D. 2012. The sliming: how processed beef trimmings got rebranded, again and again, and again. Slate October 25, 2012. Available at: https://slate.com/news-and-politics/2012/10/history-of-pinkslime-how-partially-defatted-chopped-beef-got-rebranded-again-and-again-and-again.html

Enyinda, C.I. 2009. Modelling risk management in the pharmaceutical industry global supply chain logistics using analytic hierarchy process model. PhD-thesis, North Dakota State University, Fargo, ND, USA.

Fischer, C., M. Hartmann, N. Reynolds, P. Leat, C. Revoredo-Giha, M. Henchion and A. Gracia. 2009. Factors influencing contractual choice and sustainable relationships in European agri-food supply chains. European Review of Agricultural Economics 36(4): 541-569.

Gereffi, G. 2014. Global value chains in a post-Washington Consensus world. Review of International Political Economy 21(1): 9-37.

Gopal, P. and J. Thakkar. 2015. Development of composite sustainable supply chain performance index for the automobile industry. International Journal of Sustainable Engineering 8(6): 366-385.

Gray, A.W. and M.D. Boehlje. 2005. Risk sharing and transactions costs in producer-processor supply chains. Choices 20(4): 281-286.

Handayati, Y., T.M. Simatupang and T. Perdana. 2015. Agri-food supply chain coordination: the state-ofthe-art and recent developments. Logistics Research 8(1): 5.

Hashemi, A., T. Butcher and P. Chhetri. 2013. A modelling framework for the analysis of supply chain complexity using product design and demand characteristics. International Journal of Engineering, Science and Technology 5(2): 150-164.

Hobbs, J.E. 1996. A transaction cost approach to supply chain management. Supply Chain Management: an International Journal 1(2): 15-27.

Igumbor, E.U., D. Sanders, T.R. Puoane, L. Tsolekile, C. Schwarz, C. Purdy and C. Hawkes. 2012. 'Big food,' the consumer food environment, health, and the policy response in South Africa. PLoS Medicine 9(7): e1001253. https://doi.org/10.1371/journal.pmed.1001253

Jordaan, D. du P.S. 2017. Agribusiness value-chain risk, fragility and coordination strategies: case studies of South African value chains. PhD-thesis, University of Pretoria, Pretoria, South Africa. 
Jordaan, D. du P.S. and J.F. Kirsten. 2019. Measuring the fragility of agribusiness value chains: a case study of the South African lamb chain. International Food and Agribusiness Management Review 22(1): 137-154.

Jüttner, U. 2005. Supply chain risk management: Understanding the business requirements from a practitioner perspective. The International Journal of Logistics Management 16(1): 120-141.

Jüttner, U., H. Peck and M. Christopher. 2003. Supply chain risk management: outlining an agenda for future research. International Journal of Logistics: Research and Applications 6(4): 197-210.

Kembro, J. 2015. Exploring information sharing in the extended supply chain: an interdependence perspective. Supply Chain Management: an International Journal 20(4): 455-470. https://doi.org/10.1108/SCM07-2014-0252

Kembro, J., K. Selviaridis and D. Näslund. 2014. Theoretical perspectives on information sharing in supply chains: a systematic literature review and conceptual framework. Supply Chain Management: an International Journal 19(5-6): 609-625.

King, R.P., M. Boehlje, M.L. Cook and S.T. Sonka. 2010. Agribusiness economics and management. American Journal of Agricultural Economics 92(2): 554-570.

Kirsten, J.F., A.M. Karaan and A.R. Dorward. 2009. Introduction to the economics of institutions. In: J.F. Kirsten, A.R. Dorward, C. Poulton and N. Vick (eds.) Institutional economics perspectives on African agricultural development. International Food Policy Research Institute, Washington, DC, USA, pp. 35-74.

Kleindorfer, P.R. and G.H. Saad. 2005. Managing disruption risks in supply chains. Production and Operations Management 14(1): 53-68.

Lazzarini, S., F. Chaddad and M. Cook. 2001. Integrating supply chain and network analyses: the study of net chains. Journal on Chain and Network Science 1(1): 7-22.

Leat, P. and C. Revoredo-Giha. 2013. Risk and resilience in agri-food supply chains: the case of the ASDA PorkLink supply chain in Scotland. Supply Chain Management: an International Journal 18(2): 219-231.

Liu, Z.L., T.D. Anderson and J.M. Cruz. 2012. Consumer environmental awareness and competition in twostage supply chains. European Journal of Operational Research 218(3): 602-613.

Louw, M., T. Davids and N. Scheltema. 2017. Broiler production in South Africa: is there space for smallholders in the commercial chicken coup? Development Southern Africa 34(5): 564-574.

Martinez, S.W. 1999. Vertical coordination in the pork and broiler industries: implications for pork and chicken products. Agricultural Economic Reports 34031. Economic Research Service, United States Department of Agriculture, Washington, DC, USA.

Martinez, S.W. 2002a. A comparison of vertical coordination in the US poultry, egg, and pork industries. Agricultural Information Bulletins 33773. Economic Research Service, United States Department of Agriculture, Washington, DC, USA.

Martinez, S.W. 2002b. Vertical coordination of marketing systems: lessons from the poultry, egg, and pork industries. Agricultural Economic Reports 34051. Economic Research Service, United States Department of Agriculture, Washington, DC, USA.

Martinez, S.W. and K.D. Zering. 2004. Pork quality and the role of market organisation. Agricultural Economic Reports 33973. Economic Research Service, United States Department of Agriculture, Washington, DC, USA.

Martinez-Jaramillo S., O.P. Pérez, F.A. Embriz and F.L.G. Dey. 2010. Systemic risk, financial contagion and financial fragility. Journal of Economic Dynamics and Control 34(11): 2358-2374.

Maslaric, M., T. Backalic. S. Nikolicic and D. Mircetic. 2013. Assessing the trade-off between lean and resilience through supply chain risk management. International Journal of Industrial Engineering and Management 4(4): 229-236.

Masten, S.E. 1996. Empirical research in transaction cost economics: challenges, progress, directions. In: J. Groenewegen (ed.) Transaction cost economics and beyond. Springer, Dordrecht, the Netherlands, pp. 43-64.

Mentzer, J.T., W. DeWitt, J.S. Keebler, S. Min, N.W. Nix, C.D. Smith and Z.G. Zachariah. 2001. Defining supply chain management. Journal of Business Logistic 22(2): 1-25. 
Migliore, G., G. Schifani and L. Cembalo. 2015. Opening the black box of food quality in the short supply chain: effects of conventions of quality on consumer choice. Food Quality and Preference 39: 141-146.

Nair, A., R. Narasimhan and T.Y. Choi. 2009. Supply networks as a complex adaptive system: toward simulation-based theory building on evolutionary decision-making. Decision Sciences 40(4): 783-815.

Ncube, P. 2018. The Southern African poultry value chain: corporate strategies, investments and agroindustrial policies. Development Southern Africa 35(3): 369-387.

Nishat Faisal, M., D.K. Banwet and R. Shankar. 2006. Supply chain risk mitigation: modeling enablers. Business Process Management Journal 12(4): 535-552.

Nooraie, S.V. and M.M. Parast. 2016. Mitigating supply chain disruptions through the assessment of trade-offs among risks, costs and investments in capabilities. International Journal of Production Economics 171: 8-21.

Norrman, A. and U. Jansson. 2004. Ericsson's proactive supply chain risk management approach after a serious sub-supplier accident. International Journal of Physical Distribution \& Logistics Management 34(5): 434-456.

Paulraj, A. and I.J. Chen. 2007. Environmental uncertainty and strategic supply management: a resource dependence perspective and performance implications. Journal of Supply Chain Management 43(3): $29-42$.

Peck, H. 2005. Drivers of supply chain vulnerability: an integrated framework. International Journal of Physical Distribution \& Logistics Management 35(4): 210-232.

Petersen, K.J., R.B. Handfield, B. Lawson and P.D. Cousins. 2008. Buyer dependency and relational capital formation: the mediating effects of socialization processes and supplier integration. Journal of Supply Chain Management 44(4): 53-65.

Peterson, H.C., A. Wysocki and S.B. Harsh. 2001. Strategic choice along the vertical coordination continuum. The International Food and Agribusiness Management Review 4(2): 149-166.

Pettit, T.J., K.L. Croxton and J. Fiksel. 2019. The evolution of resilience in supply chain management: a retrospective on ensuring supply chain resilience. Journal of Bussiness Logistics 40: 56-65. https:// doi.org/10.1111/jbl.12202

Pieri, F. and E. Zaninotto. 2013. Vertical integration and efficiency: an application to the Italian machine tool industry. Small Business Economics 40(2): 397-416.

Raynaud, E., L. Sauvee and E. Valceschini. 2005. Alignment between quality enforcement devices and governance structures in the agro-food vertical chains. Journal of Management \& Governance 9(1): 47-77.

Segerstedt, A.,T. Olofsson, L. Bankvall, L.E. Bygballe, A. Dubois and M. Jahre. 2010. Interdependence in supply chains and projects in construction. Supply Chain Management: an International Journal 15(5): 385-393.

Serdarasan, S. 2013. A review of supply chain complexity drivers. Computers \& Industrial Engineering 66(3): 533-540.

Sexton, R.J. 2012. Market power, misconceptions, and modern agricultural markets. American Journal of Agricultural Economics 95(2): 209-219.

Sheffi, Y. and J.B. Rice Jr. 2005. A supply chain view of the resilient enterprise. Massachusetts Institute of Technology Sloan Management Review 47(1): 41.

Simba, S., W. Niemann, T. Kotzé and A. Agigi. 2017. Supply chain risk management processes for resilience: a study of South African grocery manufacturers. Journal of Transport and Supply Chain Management 11(1): 1-13.

Skipper, J.B., C.W. Craighead, T.A. Byrd and R.K. Rainer 2008. Towards a theoretical foundation of supply network interdependence and technology-enabled coordination strategies. International Journal of Physical Distribution \& Logistics Management 38(1): 39-56.

Sodhi, M.S., B.G. Son and C.S. Tang. 2012. Researchers' perspectives on supply chain risk management. Production and Operations Management 21(1): 1-13. 
South Africa Department of Agriculture, Forestry and Fisheries (DAFF). 2018. A profile of the South African egg market value chain - 2019. DAFF, Pretoria, South Africa. Available at: https://www.dalrrd.gov. za/doaDev/sideMenu/Marketing/Annual\%20Publications/Egg\%20Market\%20Value\%20Chain\%20 Profile\%202019.pdf

South African Poultry Association (SAPA). 2017. South African Poultry Association 2017 industry profile. SAPA, Randburg, South Africa.

Sporleder, T.L. and M.A. Boland. 2011. Exclusivity of agrifood supply chains: seven fundamental economic characteristics. International Food and Agribusiness Management Review 14(5): 27-51.

Stecke, K.E. and S. Kumar. 2009. Sources of supply chain disruptions, factors that breed vulnerability, and mitigating strategies. Journal of Marketing Channels 16(3): 193-226.

Stonebraker, P.W., J. Goldhar and G. Nassos. 2007. Toward a framework of supply chain sustainability: the fragility index. In: Proceedings of the Production Operations Management Annual Conference. May, 2007. Dallas, TX, USA.

Stonebraker, P.W., J. Goldhar and G. Nassos. 2009. Weak links in the supply chain: measuring fragility and sustainability. Journal of Manufacturing Technology Management 20(2): 161-177.

Storey, J., C. Emberson, J. Godsell and A. Harrison. 2006. Supply chain management: theory, practice and future challenges. International Journal of Operations \& Production Management 26(7): 754-774.

Taleb, N.N. 2012. Antifragile: how to live in a world we don't understand. Allen Lane, London, UK.

Taleb, N.N., E. Canetti, T. Kinda, E. Loukoianova and C. Schmieder. 2012. A new heuristic measure of fragility and tail risks: application to stress testing. IMF Working Paper No. 12/216. Available at SSRN: https://ssrn.com/abstract=2156095

Tang, C.S. 2006. Perspectives in supply chain risk management. International Journal of Production Economics 103(2): 451-488.

Thompson, J.D. 2003. Organizations in action: social science bases of administrative theory, $1^{\text {st }}$ edition. Transaction Publishers, NJ, USA.

Ulrich, D. and J.B. Barney. 1984. Perspectives in organisations: resource dependence, efficiency and population. Academy of Management Review 9(3): 471-481.

Van Plaggenhoef, W. 2007. Integration and self-regulation of quality management in Dutch agri-food supply chains: a cross-chain analysis of the poultry meat, the fruit and vegetable and the flower and potted plant chains. International Chains and Networks 4: 296. https://doi.org/10.3920/978-90-8686-627-4

Vanany, I., S. Zailani and N. Pujawan. 2009. Supply chain risk management: literature review and future research. International Journal of Information Systems and Supply Chain Management 2(1): 16-33.

Vilko, J., P. Ritala and J. Edelmann. 2014. On uncertainty in supply chain risk management. The International Journal of Logistics Management 25(1): 3-19.

Vlajic, J.V., J.G. Van der Vorst and E. Hendrix. 2010. On robustness in food supply chain networks. In: J. Trienekens, J. Top, J. Van der Vorst and A. Buelens (eds.) Towards effective food supply chains. Wageningen Academic Publishers, Wageningen, the Netherlands, pp. 63-82.

Vlajic, J.V., J.G. Van der Vorst and R. Haijema. 2012. A framework for designing robust food supply chains. International Journal of Production Economics 137(1): 176-189.

Vlajic, J.V., S.W. Van Lokven, R. Haijema and J.G. Van der Vorst. 2013. Using vulnerability performance indicators to attain food supply chain robustness. Production Planning \& Control 24(8-9): 785-799

Wagner, S.M. and C. Bode. 2006. An empirical investigation into supply chain vulnerability. Journal of Purchasing and Supply Management 12(6): 301-312.

Wagner, S.M. and C. Bode. 2008. An empirical examination of supply chain performance along several dimensions of risk. Journal of Business Logistics 29(1): 307-325.

Wagner, S.M. and C. Bode. 2009. Dominant risks and risk management practices in supply chains. In: G.A. Zsidisin and B. Ritchie (eds.) Supply chain risk. Springer, Boston, MA, USA. https://doi. org/10.1007/978-0-387-79934-6_17

Wagner, S.M. and N. Neshat. 2010. Assessing the vulnerability of supply chains using graph theory. International Journal of Production Economics 126(1): 121-129.

Wagner, S.M. and N. Neshat. 2012. A comparison of supply chain vulnerability indices for different categories of firms. International Journal of Production Research 50(11): 2877-2891. 
Wang, E.T., J.C. Tai and H.-L. Wei. 2006. A virtual integration theory of improved supply-chain performance. Journal of Management Information Systems 23(2): 41-64.

Watabaji, M., A. Molnar and X. Gellynck. 2016. Integrative role of value chain governance: evidence from the malt barley value chain in Ethiopia. Journal of the Institute of Brewing 122(4): 670-681.

Weseen, S., J. Hobbs and W.A. Kerr. 2014. Reducing hold-up risks in ethanol supply chains: a transaction cost perspective. International Food and Agribusiness Management Review 17(2): 1-24.

Wever, M., N. Wognum, J. Trienekens and O. Omta. 2010. Alignment between chain quality management and chain governance in EU pork supply chains: a transaction-cost-economics perspective. Meat Science 84(2): 228-237.

Wever, M., N. Wognum, J. Trienekens and O. Omta. 2012a. Managing transaction risks in interdependent supply chains: an extended transaction cost economics perspective. Journal on Chain and Network Science 12(3): 243-260.

Wever, M., N. Wognum, J. Trienekens and O. Omta. 2012b. Supply chain-wide consequences of transaction risks and their contractual solutions: towards an extended transaction cost economics framework. Journal of Supply Chain Management 48(1): 73-91.

Williamson, O.E. 1979. Transaction-cost economics: the governance of contractual relations. The Journal of Law and Economics 22(2): 233-261.

Williamson, O.E. 1987. Transaction cost economics: the comparative contracting perspective. Journal of Economic Behavior \& Organization 8(4): 617-625.

Williamson, O.E. 2008. Transaction cost economics. In: C. Ménard and M.M. Shirley (eds.) Handbook of new institutional economics. Springer, Berlin, Heidelberg, Germany. https://doi.org/10.1007/9783-540-69305-5_4

Ye, F., Y. Li and Q. Yang. 2018. Designing coordination contract for biofuel supply chain in China. Resources, Conservation and Recycling 128: 306-314.

Yeboah, N.E., Y. Feng, O.-S. Daniel and N.B. Joseph. 2014. Agricultural supply chain risk identification: a case finding from Ghana. Journal of Management and Strategy 5(2): 31-48.

Zhong, Z., C. Zhang, F. Jia and J. Bijman. 2018. Vertical coordination and cooperative member benefits: case studies of four dairy farmers' cooperatives in China. Journal of Cleaner Production 172: 2266-2277.

Zsidisin, G.A., S.A. Melnyk and G.L. Ragatz. 2005. An institutional theory perspective of business continuity planning for purchasing and supply management. International Journal of Production Research 43(16): 3401-3420. 
